\title{
Community shelter use in response to two benthic decapod predators in the Long Island Sound
}

\author{
David M Hudson ${ }^{\text {Corresp., }}{ }^{1,2}{ }^{\text {， Dugan Reagan }}{ }^{1}$, Joseph F Crivello ${ }^{1}$ \\ 1 Department of Physiology and Neurobiology, University of Connecticut, Storrs, Connecticut, United States \\ 2 Division of Science, Mathematics, and Health Professions, Atlanta Metropolitan State College, Atlanta, Georgia, United States \\ Corresponding Author: David M Hudson \\ Email address: dhudson@atlm.edu
}

To investigate community shelter effects of two invasive decapod species, Hemigrapsus sanguineus and Carcinus maenas, in the Long Island Sound (LIS), we deployed artificial shelters in the intertidal and immediate subtidal zones. These consisted of five groups during the summer: a control, a resident $H$. sanguineus male or female group, and a resident $C$. maenas male or female group. We quantified utilization of the shelters at 24 hours by counting crabs and fish present. We found significant avoidance of $H$. sanguineus in the field by benthic hermit crabs (Pagurus spp.) and significant avoidance of $C$. maenas by the seaboard goby (Gobiosoma ginsburgi). The grubby (Myoxocephalus aenaeus) avoided neither treatment, probably since it tends to be a predator of invertebrates. $H$. sanguineus avoided $C$. maenas treatments, whereas $C$. maenas did not avoid any treatment. Seasonal deployments in the subtidal indicated cohabitation of a number of benthic species in the LIS, with peak shelter use corresponding with increased predation and likely reproductive activity in spring and summer for green crabs ( $C$. maenas), hermit crabs (Pagurus spp.), seaboard gobies (G. ginsburgi), and grubbies (Myoxocephalus aenaeus). 
1 Community shelter use in response to two benthic decapod predators in the Long Island Sound.

2

3 David M. Hudson ${ }^{1,2 *}$, Dugan Reagan ${ }^{1}$, and Joseph F. Crivello ${ }^{1}$

$4 \quad{ }^{1}$ University of Connecticut, Dept. of Physiology and Neurobiology, 75 N. Eagleville Rd. U-

5 3156, Storrs, CT 06269-3156 USA

$6{ }^{2}$ Atlanta Metropolitan State College, Division of Science, Mathematics, and Health Professions,

7 Atlanta, GA, 30310 USA

8 *Corresponding Author: dmhudson@gmail.com

\section{Abstract}

13 To investigate community shelter effects of two invasive decapod species, Hemigrapsus

14 sanguineus and Carcinus maenas, in the Long Island Sound (LIS), we deployed artificial shelters

15 in the intertidal and immediate subtidal zones. These consisted of five groups during the

16 summer: a control, a resident $H$. sanguineus male or female group, and a resident $C$. maenas

17 male or female group. We quantified utilization of the shelters at 24 hours by counting crabs and

18 fish present. We found significant avoidance of $H$. sanguineus in the field by benthic hermit

19 crabs (Pagurus spp.) and significant avoidance of C. maenas by the seaboard goby (Gobiosoma

20 ginsburgi). The grubby (Myoxocephalus aenaeus) avoided neither treatment, probably since it

21 tends to be a predator of invertebrates. H. sanguineus avoided C. maenas treatments, whereas $C$.

22 maenas did not avoid any treatment. Seasonal deployments in the subtidal indicated cohabitation

23 of a number of benthic species in the LIS, with peak shelter use corresponding with increased 
24 predation and likely reproductive activity in spring and summer for green crabs (C. maenas),

25 hermit crabs (Pagurus spp.), seaboard gobies (G. ginsburgi), and grubbies (Myoxocephalus 26 aenaeus).

\section{Introduction}

In marine systems, the availability of shelter and risk avoidance when choosing shelter has a profound effect for many animals on growth rates, survival, avoidance of predators, and particularly mating systems for decapod crustaceans (Atema, 1986; Perkins-Visser, Wolcott \& Wolcott, 1996; Beck, 1997; Wieters et al., 2009). As shelter is often at a premium (O’Neill \& Cobb, 1979), conferral of group defense can be beneficial. For example, juvenile spiny lobsters

34 in the Florida Key exhibit cohabitation within and among species within the same shelter

35 (Childress \& Herrnkind, 2001a; Childress \& Herrnkind, 2001b; Jordan, 2010). As this can result

36 in negative competitive interactions, this requires the animal to evaluate the risk associated with

37 cohabitation (Jordan, 2010). Many marine species have to select new shelter when they migrate

38 into, out of, and within estuaries seasonally or with changes in abiotic factors such as dissolved

$39 \mathrm{O}_{2}$ or salinity (Pörtner, 2001; Ortiz-León, de Jesus-Navarrete \& Sosa Cordero, 2007). Shelter use

40 by different benthic species varies by season, since the specific shelter challenges faced by

41 resident species with the presence of migratory species or influence of non-native species can

42 vary by time of year and competition between animals (Perkins-Visser, Wolcott \& Wolcott,

43 1996; Childress \& Herrnkind, 2001a). In this study, we show Long Island Sound (LIS) benthic

44 species not only modify their shelter use by season, but also by the presence of invasive decapod 45 predators or competitors. 
Visser, Wolcott \& Wolcott, 1996; Childress \& Herrnkind, 2001a). Particularly, decapod depending on the sex of the individual (Hines, Lipcius \& Haddon, 1987; Karnofsky, Atema \& Elgin, 1989), and can behaviorally respond to the presence of only one individual in a shelter

51 (Cowan \& Atema, 1990). Shelter's importance is also evident since mortality in the losing group can increase when interspecific and intraspecific competition in marine systems for quality shelter limits its accessibility (O’Neill \& Cobb, 1979; Cobb, 1981; Richards \& Cobb, 1986; Grove \& Woodin, 1996; Brousseau, Kriksciun \& Baglivo, 2003; Jordan, 2010). In the LIS intertidal and subtidal zones, both the European green crab, Carcinus maenas (Linnaeus, 1758), and the Asian shore crab, Hemigrapsus sanguineus (De Haan, 1835) are invasive species. These species are competitors for space and food with native species (MacDonald et al., 2007; Griffen, Guy \& Buck, 2008), requiring the identification of those finfish and crustacean species that may also utilize the same shelter and are likely to be affected in currently-invaded areas in order to predict likely future effects on community members.

The invasion of $H$. sanguineus to the western North Atlantic Ocean supplanted the earlier invader, C. maenas, and H. sanguineus is currently invading Europe along with its congener, Hemigrapsus takanoi (Lohrer \& Whitlatch, 2002; Asakura \& Watanabe, 2005; van den Brink,

64 Wijnhoven \& McLay, 2012; Gothland et al., 2013; Gothland et al., 2014). The Asian shore crab, H. sanguineus, was first found on the U.S. east coast in New Jersey in 1988 (Williams \& McDermott, 1990). Since then, it became the most dominant crab in the intertidal zone of the northwest Atlantic Ocean, with densities up to 300 individuals $/ \mathrm{m}^{2}$ (McDermott, 1998; Lohrer \& 68 Whitlatch, 2002; Kraemer et al., 2007). It is found subtidally, but in lower densities (pers. obs.). 
69 H. sanguineus is a generalist omnivore and can survive in a wide range of salinities (Depledge,

70 1984; Hudson, 2011). It prefers rocky substrate to sand and settles in the presence of conspecific

71 adult olfactory cues (Lohrer et al., 2000; Steinberg, Epifanio \& Andon, 2007; Hudson, 2011;

72 Rasch \& O’Connor, 2012). In the intertidal zone, predation occurs from both terrestrial and

73 marine sources, which makes $H$. sanguineus a vigorous intertidal competitor for space and

74 shelter due to its avoidance of risk during shelter choice and aggression toward smaller

75 interspecific competitors (Jones \& Shulman, 2008; Wieters et al., 2009; Rasch \& O’Connor,

76 2012; Peterson et al., 2014). As such, we wanted to see if the presence of this species impacted

77 the use of shelter by LIS community members in the field.

78 The previous intertidal resident invader, the European green crab, C. maenas, is still seen

79 in the intertidal and subtidal zone in the Long Island Sound, though in lower densities than in its

80 home range (Amaral et al., 2009). The arrival of C. maenas occurred sometime pre-1817 (Say,

81 1817) and that of $H$. sanguineus in the late 1980s (Williams and McDermott, 1990). However, $C$.

82 maenas itself is still a potent invasive species worldwide and on the North American continent

83 (Freeman \& Byers, 2006; Darling et al., 2008). As benthic animal survival is so tied to the

84 availability and ability to maintain shelter (O’Neill \& Cobb, 1979; Cobb, 1981; Richards \&

85 Cobb, 1986; Grove \& Woodin, 1996; Brousseau, Kriksciun \& Baglivo, 2003; Jordan, 2010), our

86 main focus for this work was to elucidate the sublethal choice effect that these two species have

87 on the use of shelter by native fauna in the LIS. This information can be used in areas where both

88 of these species are still relatively new invaders, to allow for an informed management strategy

89 of native species.

90 Our main objectives for this study were to: (1) capture any sexual variability in shelter

91 use by decapods, as described above for other decapods, which was accomplished through a field 
92 experiment with empty PVC artificial shelters as a control, and a male and female treatment for

93 each of the two types of crab (H. sanguineus and C. maenas), for a total of five treatments; and

94 (2) use these deployments and complementary laboratory studies (to better explain any effects of

95 C. maenas and $H$. sanguineus on one another) to predict which LIS community species found in 96 our shelters will be most affected by the presence of one of these invaders.

\section{Materials and Methods}

\section{Community Shelter Use}

100 To measure Long Island Sound (LIS) community shelter use differences in the field, we

101 deployed a field shelter behavior assay. Benthic animals in the LIS are dependent on shelter for

102 survival, so these shelter tubes imitate shelters that are unoccupied or occupied to test the

103 potential for cohabitation with two important intertidal invaders in a shelter-limited area adjacent

104 to habitat with ample shelter (small boulders). Replicates of the field apparatus (Figure 1B) were

105 deployed during the summer of 2009 for approximately 24 hours in the immediate subtidal zone

106 ( $\sim 1 \mathrm{~m}$ depth) and intertidal zone ( $0.25 \mathrm{~m}$ above Mean Lower Low Water (MLLW), the lowest

107 low tide daily) of the northwest end of Pine Island, Groton, CT USA ( $41^{\circ} 18^{\prime} 47.434^{\prime \prime} \mathrm{N}$,

$\left.10872^{\circ} 3^{\prime} 36.216^{\prime \prime} \mathrm{W}\right)$. The tubes were at least 1.5 meters apart, and were not attached to one another,

109 but were all deployed along a uniform depth parallel to a shoreline with similar bottom

110 characteristics along the length of the deployment. In cursory diving surveys, mobile animals

111 seemed varied by species and fairly evenly distributed along the deployment location. This

112 should have avoided the initial species approach phenomenon as much as possible. We operated

113 under Connecticut Department of Environmental Protection Scientific Collector's Permits \# SC-

11406040 and \# SC-09015. Other researchers have quantified decapods' responses artificial shelter 
115 with conspecific presence (Nevitt et al. 2000, Childress \& Herrnkind 2001a), so the apparatus

116 was designed to fit the target species. The apparatuses were constructed with weathered (3+

117 years exposed to the elements) $5.08 \mathrm{~cm}$ PVC tubing, with two $30 \mathrm{~cm}$ sections connected by a

118 PVC joint. Cages constructed of $0.5 \mathrm{~cm}$ plastic mesh were used to isolate the live treatment

119 animal inside the tube. We saw some influence of individual presence on one another with

120 different species in the laboratory, and the original idea was to pump (expensively) water over an

121 individual in the field and into the tubes. We did not have sufficient funding for that design, so

122 we were confident in using a single "bait" animal. Control tubes were deployed with an empty

123 cage to provide internal structure, and all tubes were anchored with U-shaped steel rebar. After a

124 24-hour soak, divers capped each end, and deployed the next apparatus. The tubes were deployed

125 over a two-week period with random assignment of treatments each day in groups of 20 to 25

126 tubes, until 60 replicates were reached for each treatment. Capped tubes were quantified each

127 day for the presence of crab and arthropod species, and other macroinvertebrates and vertebrates.

128 Catch Per Unit Effort (CPUE) is reported here as percent of shelters used (\%) calculated as the

129 number of animals caught in each artificial shelter treatment, divided by the number of shelters

130 for that treatment (60 per treatment). Data was analyzed in Systat 12.0 via one-way ANOVA,

131 and Tukey's Post-Hoc Test (alpha $=0.05)$.

132 We took two approaches: (1) to capture animals that may only be using subtidal shelters

133 seasonally, we deployed the artificial shelters four times over the course of a year. (2) In order to

134 gain a sense for the intertidal use of shelter, which is most used in the summer months in the LIS,

135 we also deployed intertidal experimental artificial shelters during the summer.

136

137 Seasonal subtidal deployment 
139 the overall effect on community shelter use across four seasons for this species in the subtidal

140 zone. These shelters were deployed subtidally ( $\sim 1 \mathrm{~m}$ depth) across four seasons in 2009 , with

141 control, and live male and female $H$. sanguineus bait treatments (total $\mathrm{N}=180$ for each

142 deployment).

143

144 Summer subtidal and intertidal deployment

145 In the summer months two additional treatments; live male and live female Carcinus

146 maenas bait treatments were added. Thus, five treatments were used, along with the same

147 control, live male and live female $H$. sanguineus treatments as already deployed in the seasonal

148 deployment. We deployed the artificial shelters both in the subtidal and in the intertidal zone. As

149 such, for summer experiments, each treatment was deployed in replicates of 60 both subtidally

150 and intertidally (total $\mathrm{N}=300$ intertidal, $\mathrm{N}=300$ subtidal). A two-way ANOVA with tidal

151 deployment and treatment was used to determine the interaction between treatment and tidal

152 deployment, and size differences between subtidal and intertidal deployments were analyzed

153 with Student's t-test.

Shelter interaction for $H$. sanguineus and C. maenas

156 To further determine size effects on dominance and shelter use of the two invaders,

157 shelter competition experiments utilized size ratio for interspecific and intraspecific shelter

158 dominance between $H$. sanguineus and C. maenas. Multiple carapace width ratios,

159 approximately $3: 1,2: 1,1: 1,1: 2$, and 1:3 in replicates of 10 , were used for a one-on-one

160 laboratory shelter competition experiment that lasted 24 hours. We compared intraspecific $(H$. 
161 sanguineus or C. maenas versus member of the same species) and interspecific (H. sanguineus

162 versus $C$. maenas) competition trials. Shelter use frequency differences between competitors

163 were analyzed using Fisher's Exact Test. The effect of size ratio of competitors on "winner" and

164 mortality was analyzed by a linear regression in $\mathrm{R}$ statistical software. Crabs were introduced to

165 a plastic $18 \mathrm{~cm} \mathrm{x} 31 \mathrm{~cm}$ arena with $2.5 \mathrm{~cm}$ of sand substrate and a $10 \mathrm{~cm} \times 5.0 \mathrm{~cm}$ shelter made

166 from $6.35 \mathrm{~cm}$ PVC pipe with a quarter of its circumference removed arranged in the container to

167 have only one useable opening (Figure 1B). A clear piece of plexiglass was placed over the

168 container to prohibit escape, and an airstone oxygenated the tank. Each competition experiment

169 involved placing two individuals on opposite sides of the container, width-wise, while the shelter

170 was opposite both of the individuals, length-wise. The two individuals in the container were then

171 allowed to compete for the shelter over a 24-hour period, after which the positions of the crabs

172 were noted as in the shelter or outside the shelter. Injuries to the claws or legs of each crab due to

173 fighting were recorded. The plastic container, PVC pipe, and sand were cleaned with $10 \%$ bleach

174 between replicates.

\section{Results}

177 Community Shelter Use

178 Four species commonly cohabitated in the subtidal artificial shelters: the green crab

179 Carcinus maenas, hermit crabs Pagurus spp. (grouped by genus), the seaboard goby Gobiosoma

180 ginsburgi, and the grubby Myoxocephalus aenaeus. Subtidal deployment caught very few

181 Hemigrapsus sanguineus individuals (11 individuals in 960 replicates deployed). Seasonal

182 change in shelter use (with no crabs present, or with $H$. sanguineus male, and $H$. sanguineus

183 female present) occurred amongst the four most collected species (Fig. 2). 
seen for $C$. maenas subtidal shelter preference by treatment. There is no indication of habitat areas were not significantly different $($ mean $=25.4 \mathrm{~mm}$ for intertidal, mean $=25.64 \mathrm{~mm}$ for subtidal, Student's t-test, $\mathrm{p}=0.95)$. However, significant seasonal shelter usage changes were observed in $C$. maenas (one-way ANOVA, $\mathrm{F}=7.38,3$ d.f., $\mathrm{p}<0.001, \mathrm{~N}=721$ ). Spring shelter usage was nearly triple that of winter (Tukey's Post-Hoc Test, alpha 0.05, p $<0.001$ ), which then significantly (Tukey's Post-Hoc Test, alpha $0.05, \mathrm{p}<0.05$ ) dropped by $54 \%$ in the summer deployment (Fig. 2A). C. maenas also doubled its shelter use in autumn over the previous winter

193 (Tukey's Post-Hoc Test, alpha 0.05, $\mathrm{p}<0.05$ over winter values) (Fig. 2A). When all four

194 seasons' subtidal data are pooled, in which there were control, $H$. sanguineus male and $H$. sanguineus female treatments, C. maenas showed a trend for avoidance of the male $H$. sanguineus treatment over the control (one-way ANOVA, $\mathrm{F}=2.71,2$ d.f., $\mathrm{p}=0.067, \mathrm{~N}=721$, Tukey Post-Hoc $\mathrm{p}=0.068, \mathrm{p}=0.200$, for $H$. sanguineus male and $H$. sanguineus female treatments, respectively). pairwise comparisons by Tukey's Post-Hoc Test, alpha 0.05, $\mathrm{p}<0.001$ ), with spring shelter usage 23 times that of winter, then a subsequent significant dip during the summer by about one third, and further dip from spring values during autumn to about 11 percent shelter use (Fig. 2B).

204 The seaboard goby Gobiosoma ginsburgi (Fig. 2C) showed a significant seasonal signal as well 205 (one-way ANOVA, $\mathrm{F}=32.425,3$ d.f., $\mathrm{p}<0.001, \mathrm{~N}=721$; Table 1B; all pairwise comparisions 
207 about 23 times from winter to spring, and a doubling of spring values during summer. Similarly,

208 Myoxocephalus aenaeus (Fig. 2D) significantly (one-way ANOVA, $\mathrm{F}=5.061,3$ d.f., $\mathrm{p}=0.002$,

$209 \mathrm{~N}=721$ ) increased its shelter use during summer versus winter and spring (Tukey's Post-Hoc

210 Test, alpha $0.05, \mathrm{p}<0.005$ ) and decreased its shelter use in autumn (Tukey's Post-Hoc Test,

211 alpha $0.05, \mathrm{p}<0.05)$.

212 Organisms were only found in sufficient numbers to merit comparison by treatment in

213 summer. As for subtidal summer shelter use, Pagurus spp. showed preference for treatments

214 (one-way ANOVA, $\mathrm{F}=4.017,4$ d.f., $\mathrm{p}=0.003, \mathrm{~N}=300$ ), specifically avoiding both $H$.

215 sanguineus male and female treatments (Tukey's Post-Hoc Test, alpha $0.05, \mathrm{p}<0.03$ ) in the

216 subtidal (Fig. 3A) and using these shelters 1 to 2 times less often than others. The goby $G$.

217 ginsburgi also showed preference for specific treatment shelters (one-way ANOVA, F = 15.277,

2184 d.f., $\mathrm{p}<0.001, \mathrm{~N}=300$ ) by avoiding completely (Tukey's Post-Hoc Test, alpha $0.05, \mathrm{p}<$

219 0.001) both of the C. maenas treatments (Fig. 3B). The grubby M. aenaeus did not show

220 preference (one-way ANOVA, $\mathrm{F}=0.823,4$ d.f., $\mathrm{p}=0.511, \mathrm{~N}=300$ ) for any treatments, and was

221 found at lower catch rates (data are in attached supplemental data).

222 Only C. maenas and H. sanguineus were found in sufficient numbers in summer intertidal

223 deployments to merit analysis by treatment. In those, C. maenas showed a significantly lower

224 intertidal shelter use (one-way ANOVA, $\mathrm{F}=29.290, \mathrm{p}<0.001, \mathrm{~N}=600$; Table $1 \mathrm{C}$ ) than subtidal

225 shelter use by a factor of about 3.6 times (Supplemental Fig. 1A). For summer deployments, no

226 significant difference nor trend (one-way ANOVA, $\mathrm{F}=1.394, \mathrm{p}=0.236, \mathrm{~N}=300$ ) was observed

227 for subtidal shelter preference by treatment in C. maenas (Supplemental Fig. 1B, 1C). $H$.

228 sanguineus exhibited the opposite pattern, with significantly lower (one-way ANOVA, F =

$22930.88,1$ d.f., $\mathrm{p}<0.001, \mathrm{~N}=600)$ subtidal shelter use ( $1 \%$ use at 3 crabs in 300 shelters) than 
230 intertidal shelter use (14\% use at 42 crabs in 300 shelters) (Supplemental Fig. 2). No comparison

231 by treatment was possible for $H$. sanguineus in subtidal treatments due to low catch rate, but

232 catch efficiency was approximately 25 percent overall in the intertidal zone.

233 In the summer intertidal experiments, differences in male and female $H$. sanguineus

234 behavior were observed. H. sanguineus males used shelters of any treatment $8.3 \%$ of the time $(\mathrm{N}$ $235=301$ shelters), but used intertidal treatments differently (one-way ANOVA, $\mathrm{F}=3.46,4$ d.f., $\mathrm{p}=$ $2360.0088, \mathrm{~N}=301)$. Males displayed a lower $(3.3 \%$ of treatment shelters) use of C. maenas male

237 (Tukey Post-Hoc, $\mathrm{p}=0.029)$ and C. maenas female ( $1.6 \%$ of total shelters) treatments (Tukey

238 Post-Hoc, $\mathrm{p}=0.011$ ) when compared to the $16.9 \%$ use of $H$. sanguineus female treatment

239 shelters (Fig. 4A). Female H. sanguineus crabs also differed significantly in use of intertidal

240 shelters (one-way ANOVA, $\mathrm{F}=2.577,4$ d.f., $\mathrm{p}=0.038, \mathrm{~N}=301$ ), but across all treatments only

241 used $4.65 \%$ of them ( $\mathrm{N}=301$ shelters). Female H. sanguineus crabs (Fig. 4B) did not choose

242 conspecific $H$. sanguineus male treatment shelters (none were used, $0 \%$ ) when compared with

243 the control $11.7 \%$ usage rate (Tukey Post-Hoc, $p=0.018$ ). There were no significant differences

244 for other treatments, perhaps due to females' low shelter usage rate.

245 When pooled regardless of sex or maturity, significant differences were found in use of

246 intertidal treatments by $H$. sanguineus (one-way ANOVA, $\mathrm{F}=5.39,4$ d.f., $\mathrm{p}=0.0003, \mathrm{~N}=306$ ).

247 In intertidal treatments, $H$. sanguineus showed no significant reduction in shelter use of either $H$.

248 sanguineus treatments over control (cage only) treatment (Tukey Post-Hoc, $\mathrm{p}>0.05$ ), sticking at

$24925 \%$ (15/60) use for control shelters, 8.33\% (5/60) use for $H$. sanguineus male treatments, and

$25025.4 \%(15 / 59)$ use for $H$. sanguineus female treatments. The greater usage of $H$. sanguineus

251 female shelters over all other crab treatment shelters is significant (H. sanguineus male, and both

252 C. maenas male and female treatments, Tukey Post-Hoc, $\mathrm{p}=0.040, \mathrm{p}=0.006, \mathrm{p}=0.002$, 
253 respectively). However, H. sanguineus did significantly decrease use of C. maenas female 254 treatment shelters to 4.84\% (3/62) (Tukey Post-Hoc, $\mathrm{p}=0.031)$, and trended (Tukey Post-Hoc, $\mathrm{p}$ $255=0.064)$ to decrease $(6.67 \%$, or $4 / 60)$ use of C. maenas male treatment shelters (Fig. 4C). When 256 subtidal and intertidal summer data are included together, these treatment differences still hold in 257 H. sanguineus residency (two-way ANOVA, $\mathrm{N}=600$, Tidal Deployment: $\mathrm{F}=32.83$, 1 d.f., $\mathrm{p}<$ 258 0.0001, Treatment: $\mathrm{F}=4.54,4$ d.f., $\mathrm{p}=0.0012$, Tidal Deployment*Treatment, $\mathrm{F}=3.698,4$ d.f., $259 \mathrm{p}=0.0055)$.

260 In laboratory direct interspecific and intraspecific individual competition, $H$. sanguineus 261 is more likely to use shelter than C. maenas (Fisher's Exact Test, $\mathrm{p}=0.0020, \mathrm{~N}=64$ ) (Fig. 5A).

262 In interspecific competition experiments, $H$. sanguineus utilized ("won") shelter $32.8 \%$ of the

263 time, whereas C. maenas only utilized shelter $9.1 \%$ of the time. While this comparison is

264 interesting on its surface, intraspecific competition puts this in context. When C. maenas

265 competes against an individual C. maenas, one of the crabs utilizes the shelter $20.1 \%$ of the time $266(\mathrm{~N}=29)$, which is not significantly different than its $9.1 \%$ shelter from when it was competing

267 against $H$. sanguineus (Fisher's Exact Test, $\mathrm{p}=0.1818, \mathrm{~N}=93$ ). The same result is observed for 268 H. sanguineus, which uses shelter at $33.3 \%$ rate $(\mathrm{N}=39)$ when competing against another $H$.

269 sanguineus, which is also not significantly different in its shelter use from when it was

270 competing against $C$. maenas (Fisher's Exact Test, $\mathrm{p}=0.3019, \mathrm{~N}=103$ ). When analyzed by the

271 effect of competitor size (Fig. 5A), H. sanguineus had a significant linear regression for shelter

272 use $\left(\mathrm{y}=-0.1835 \mathrm{x}+0.5728, \mathrm{R}^{2}=0.7449, \mathrm{p}=0.0027\right)$, but $C$. maenas' use of shelter was not

273 significant by linear regression $(\mathrm{p}=0.49)$. When crabs of the same approximate size are

274 compared (1:1 ratio group, $\mathrm{N}=17)$, H. sanguineus is significantly more likely to end up in the

275 shelter than C. maenas in interspecific trials (Fisher's Exact Test, $\mathrm{p}=0.0024, \mathrm{~N}=17$ ). However, 
276 neither is more likely to be injured or die when evenly matched by size. In interspecific trials,

277 both $H$. sanguineus and $C$. maenas were killed more often when they were smaller than the

278 opposing crab (Fig. 5B), and linear regressions explain a large amount of the variation of death

279 rates in both species. Competitor size explains $96 \%$ of the variation in death rates of $H$.

280 sanguineus $\left(\mathrm{y}=-0.3459 \mathrm{x}+-0.1805\left(\mathrm{R}^{2}=0.9607, \mathrm{p}=3.555 \times 10^{-6}\right)\right)$, and $67 \%$ of that in $C$.

281 maenas death rates $\left(\mathrm{y}=-0.3101 \mathrm{x}+0.8744\left(\mathrm{R}^{2}=0.6704, \mathrm{p}=0.0069\right)\right) . C$. maenas and H.

282 sanguineus both exhibit cannibalism when large differences in carapace width exist (see

283 supplemental data), and readily prey upon interspecific individuals.

284

285 Discussion

286 All collected species showed an increased use of shelter during warmer months, probably

287 correlated with the increased predation in this system with increasing seasonal temperature

288 (Clark, 1968; O’Neill \& Cobb, 1979) and increased need for seasonal mating and reproduction.

289 Specifically, Myoxocephalus aenaeus and Pagurus spp. shelter competition with these decapods

290 may have a greater impact during spring and summer months. Decapods Carcinus maenas and

291 the Pagurus spp. complex showed peak shelter use in the spring deployments, and both of the

292 fish species (Gobiosoma ginsburgi and M. aenaeus) peaked during summer. Other Gobiosoma

293 spp. exhibit seasonal patterns in shelter use, primarily with an increase in use of seagrass shelter

294 in July and October (King \& Sheridan, 2006). Shelter competition could further pressure $G$.

295 ginsburgi as C. maenas invades further into Canada in the North Atlantic (Roman \& Darling,

296 2007), and this shelter competition will likely affect congener Gobiosoma species in areas other

297 than the Long Island Sound (LIS) at risk of C. maenas invasion. 

numbers for seasonal or treatment analysis. The effects on the following species could not be assessed (see supplemental data): the oyster drill Nucella lapillus (6 collected), shrimp

301 Palaemontes spp. (11 collected), Crangon septemspinosa (5 collected), Cancer irroratus (5

302 collected), Panopeus herbstii (21 collected), Dyspanopeus sayi (9 collected), Xanthid crab

303 settlers (8 collected), Pholis gunnelus (1 collected), Anguilla rostrata (4 collected), Littorina

304 littorea (17 collected), and the cunner Tautogolabrus adspersus (17 collected). These collected

305 species could just be in lower numbers, not typically use shelter (not likely for the crab species),

306 or be adversely affected by the presence of the two crabs. Determining the proximal cause

307 requires further comparative work, but in the Gulf of Maine, both Hemigrapsus sanguineus and

308 C. maenas make intertidal shelter maladaptive for native species (Griffen \& Riley, 2015). If

309 there is any intraguild predation interference on other community members as Griffen and Byers

310 (2006; 2009) found between H. sanguineus and C. maenas, this merits additional investigation

311 with respect to shelter. It is also typically difficult to dislodge a resident decapod from a shelter,

312 but some species are able to do this, such as the invasive Eriocheir sinensis (Gilbey, Attrill \&

313 Coleman, 2008), and in H. sanguineus and Hemigrapsus oregonensis (Jensen, McDonald \&

314 Armstrong, 2002; Lohrer \& Whitlatch, 2002). If LIS shelter-using species cannot dislodge $H$.

315 sanguineus or C. maenas, they may just avoid the shelter altogether, resulting in our

316 undersampling of those species.

317 Species within the LIS community also responded to the treatments in our experiments.

318 Pagurus spp. avoided H. sanguineus treatments, perhaps indicating previous individual

319 experience with them as a predator. This was observed with induced responses to C. maenas

320 predators in Mytilus edulis mussels (Freeman \& Byers, 2006), and underscores how changes in 
321 dominance by each crab species could impact LIS community members, especially bivalve

322 populations. C. maenas consistently consumes more blue mussels than $H$. sanguineus and per

323 capita predation on mussels decreases with interspecific and intraspecific interference between

324 and within H. sanguineus and C. maenas (Griffen, 2006). Prior to this work, Pagurus spp. was

325 not specifically documented as potential prey of H. sanguineus (Brousseau and Baglivo, 2005),

326 but crustacean parts were found in the stomachs of H. sanguineus (Ledesma \& O'Connor, 2001).

327 Seaboard gobies, G. ginsburgi, actively avoided C. maenas treatments, indicating likely

328 predation, but showed no aversion to $H$. sanguineus present in shelters, likely since interactions

329 with this species are unlikely in the subtidal. Congener Gobiosoma spp. in non-invaded areas

330 would be expected to experience the same risk and respond in the same way. Newly-invaded

331 communities are negatively impacted by C. maenas (Walton et al., 2002), and it likely had a

332 similar impact upon its invasion to eastern North America (Freeman et al., 2014; Griffen \&

333 Riley, 2015). Although not much is known about G. ginsburgi's specific behavior, congeners

334 prefer woody debris as shelter (Everett \& Ruiz, 1993), and males guard eggs even through near-

335 lethal levels of hypoxia (Breitburg, 1992). There is high tidal flow at our study site, which are the

336 preferred conditions for congener Gobiosoma spp. (Tolley et al., 2006), but there may also be a

337 population that moves up the estuary (Schultz et al., 2003) that merits investigation. Gobiosoma

338 robustum chooses sand over seagrass shelter in the presence of a predator (Schofield, 2003);

339 therefore, a similar pattern in G. ginsburgi would mean a greater use of sand, and thus greater

340 exposure to finfish predators in areas where C. maenas is present.

341 No treatment was preferred by the grubby M. aenaeus, but it is known to be a predator of

342 small decapods (van der Meeren, 2000). The area where we deployed these shelters does not

343 have much vegetation and therefore is not a likely nursery habitat for M. aenaeus (Lazzari, 
344 Sherman \& Kanwit, 2003), but it did still show seasonal shelter use in this system. Use of these

345 shelters may be due to the slower escape response accelerations and velocities found in this

346 genus than other teleosts (Jordan, Herbert \& Steffensen, 2005), along with their role as an active

347 winter predator of small lobsters (van der Meeren, 2000). The lack of correlation of M. aenaeus

348 shelter use with treatments in our experiments demonstrated no interaction with $C$. maenas and

349 H. sanguineus.

350 In this part of the LIS, C. maenas utilized artificial shelters far more in the subtidal than

351 the intertidal, which is a reflection of its higher subtidal abundance, but this exclusively subtidal-

352 use phenomenon has not been observed in other C. maenas-invaded areas, nor in its native

353 European range (Amaral et al., 2009). The dominance of competing H. sanguineus in the

354 intertidal zone of the LIS likely decreases the availability of these shelters for native species as it 355 does in the Gulf of Maine (Griffen \& Riley, 2015). However, our field experiments do not

356 provide evidence of a $H$. sanguineus-mediated decrease in the C. maenas utilization of artificial

357 shelters in the intertidal nor subtidal, even though we saw a difference in sheltering patterns

358 between these two in the laboratory when pitted against one another. Ultimately, there is no

359 evidence from these data that $H$. sanguineus drive the difference in abundance of $C$. maenas

360 between subtidal and intertidal zones. This is consistent with work in Dutch estuaries where both

361 H. sanguineus and $H$. takanoi are invading and competing with C. maenas (van den Brink,

362 Wijnhoven \& McLay, 2012), but the decline in C. maenas seems to be due to overall decline in

363 environmental quality. However, a difference could arise if $C$. maenas cannot readily use shelter

364 as easily, and $H$. sanguineus was clearly the shelter winner in similar-sized crabs in our

365 laboratory trials. This could feed into the probable negative impact $H$. sanguineus has on early

366 settlement survival for this population of C. maenas crabs. Work done by Lohrer and Whitlatch 
367 (2002) corroborates this fact, as zero-year C. maenas were not found as often in field enclosures

368 with $H$. sanguineus. From these data and the literature, we can postulate that adult C. maenas

369 will shelter where it wants regardless of conspecific or heterospecific presence, and the

370 intertidal/subtidal pattern is likely due to interactions early in ontogeny (Lohrer \& Whitlatch 371 2002).

372 It is clear that both C. maenas and H. sanguineus avoided each another. While C. maenas 373 does not avoid shelter regardless of presence of a competitor in summer data, it does show a 374 trend for avoidance of $H$. sanguineus when all seasonal data is pooled. In fact, same-size $C$. 375 maenas are inferior shelter competitors to $H$. sanguineus in laboratory experiments. One would 376 expect a strong signal for avoidance of aggressive male crabs of conspecifics and heterospecifics 377 to avoid injury, but only $H$. sanguineus showed an avoidance of conspecific males, and it also 378 avoided shelters with either male or female C. maenas (Fig. 4C and Supplemental Figure 1).

379 That C. maenas does not show stronger avoidance of the heterospecific H. sanguineus shelters of 380 either sex makes them more likely to be negatively affected in the way we observed in the direct 381 competition studies, whereas $H$. sanguineus seems to avoid this negative interaction.

382 When $H$. sanguineus is the same size as its competitor or larger, it is not only more likely 383 to inhabit the shelter, but also more likely to kill its competitor, in this case C. maenas. C.

384 maenas will do the same to a smaller $H$. sanguineus, but we saw that when competing against a 385 conspecific C. maenas it is less likely to use shelter in the first place. H. sanguineus is likely to 386 avoid potential competitors in the field, but these data are size-dependent, consistent with earlier 387 work (Lohrer \& Whitlatch, 2002). Thus, one can conclude that this inherent lower use of shelter 388 by $C$. maenas, combined with the agonistic interaction with $H$. sanguineus, results in an 389 increased exposure of $C$. maenas to predation and desiccation in the intertidal zone and partially 
390 results in H. sanguineus dominance of this zone. The limited use of the subtidal zone by $H$.

391 sanguineus in seasonal and summer subtidal shelter deployments means that in this particular

392 system, it does not often interact with C. maenas in the subtidal. Although H. sanguineus is

393 sometimes found in large numbers subtidally, this has been in marinas not along rocky shorelines

394 (Gilman \& Grace, 2009). This adds a critical dynamic to interspecific interaction for $H$.

395 sanguineus in the intertidal zone: as it establishes in a new area, it will consume all likely

396 competitors, dominate shelter use, and result in greater exposure of competitors to both terrestrial

397 and marine predation (at high tide).

$398 \quad$ Shelter use data for $H$. sanguineus shows avoidance of potentially dangerous

399 heterospecifics (C. maenas of both sexes) and conspecific male shelters and a preference for 400 conspecific female shelters and unoccupied control shelters. This may enhance H. sanguineus'

401 survival and reproduction through avoidance of antagonistic interactions like predation and

402 competition, and indicates it can detect and use conspecific and heterospecific presence as an

403 adult in addition to as a megalopa (Steinberg, Epifanio \& Andon, 2007). In the laboratory direct

404 competition individual match-ups, adult male H. sanguineus were more likely to take over

405 vacant shelter. It is common in lobsters (O’Neill \& Cobb, 1979) and pea crabs (Grove \&

406 Woodin, 1996) to use the presence of conspecifics to determine its use of shelter, but this

407 avoidance behavior runs counter to the communal denning seen in lobster species (Zimmer-Faust

$408 \&$ Spanier 1987), which is often due to ontogeny (Childress \& Herrnkind 1996) or reproduction

409 (Bushmann \& Atema 1997). In the subtidal, other decapods seem to avoid H. sanguineus

410 treatments over the other three treatments, underscoring how the presence of this species deters

411 other decapods. Adult olfactory cues were implicated in metamorphosis and settlement of $H$.

412 sanguineus (Steinberg, Epifanio \& Andon, 2007; Rasch \& O’Connor, 2012) near conspecifics, 
413 and now we can conclude that adult presence also has an impact upon small-scale spatial

414 patterns, by indicating evaluation and mediation of risk by the adult animal.

415 From our data and the literature, changes in the abundances of these two invaders will

416 clearly result in changes to LIS community shelter use. C. maenas does not compete for shelter

417 as well as $H$. sanguineus, and the effects that the presence of each crab has on other community

418 members' use of shelter means there are different effects of each on those populations' risk of

419 predation. As such, changes in abundances of each of these two species may have different

420 shelter and seasonal effects on different LIS community members, especially as they impact

421 potential survival of G. ginsburgi and the Pagurus spp. complex, not to mention the potentially

422 negative effects of the presence of these H. sanguineus and C. maenas have on each other.

423

\section{Acknowledgements}

425

426 We thank the Department of Physiology and Neurobiology and Department of Marine Sciences

427 at the University of Connecticut, J.L. Renfro, R.W. Whitlatch, A. Moiseff, and K. Schwenk for

428 input on experimental design, and A. Hudson (González), J. S. Cobb, M. Gilman, C. McGinnis,

429 N. Hinds, I. Tornberg, and E. Limouze. L. Stefaniak provided valuable comments on the

430 manuscript. This work was impossible without the help of numerous divers and boat operators,

431 to whom the authors remain indebted.

432

433

434

435 


\section{References}

438

Amaral V, Cabral HN, Jenkins S, Hawkins S, Paula J. 2009. Comparing quality of estuarine and

nearshore intertidal habitats for Carcinus maenas. Estuarine, Coastal and Shelf Science 83:219-

441 226. DOI: 10.1016/j.ecss.2009.03.029

442

Asakura A, Watanabe S. 2005. Hemigrapsus takanoi, new species, a sibling species of the common Japanese intertidal crab H. penicillatus (Decapoda: Brachyura: Grapsoidea). Journal of Crustacean Biology 25(2):279-292. DOI: 10.1651/C-2514

446

447 Atema J. 1986. Review of sexual selection and chemical communication in the lobster, Homarus 448 americanus. Canadian Journal of Fisheries and Aquatic Sciences 43:2283-2290. DOI: 10.1139/f86-279

450

451

Beck M. 1997. A test of the generality of the effects of shelter bottlenecks in four stone crab populations. Ecology 78:2487-2503. DOI: 10.1890/0012-

9658(1997)078[2487:ATOTGO]2.0.CO;2

455 Breitburg D. 1992. Episodic hypoxia in Chesapeake Bay: Interacting effects of recruitment, 456 behavior, and physical disturbance. Ecological Monographs 62:525-525-546. DOI: 
459 Brousseau DJ, Baglivo JA. 2005. Laboratory investigations of food selection by the Asian shore 460 crab, Hemigrapsus sanguineus: algal versus animal preference. Journal of Crustacean Biology 461 25(1):130-134. DOI: $10.1651 / \mathrm{C}-2530$

462

463 Brousseau DJ, Kriksciun K, Baglivo JA. 2003. Fiddler crab burrow usage by the Asian crab, 464 Hemigrapsus sanguineus, in a Long Island Sound salt marsh. Northeastern Naturalist 10(4): 465 415-420. DOI: 10.1656/1092-6194(2003)010[0415:FCBUBT]2.0.CO;2 466

467 Bushmann PJ, Atema J. 1997. Shelter sharing and chemical courtship signals in the lobster 468 Homarus americanus. Canadian Journal of Fisheries and Aquatic Sciences 54:647-654. DOI:

469 $10.1139 / \mathrm{f} 96-302$

470

471 Childress MJ, Herrnkind WF. 1996. The ontogeny of social behavior among juvenile Caribbean 472 spiny lobsters. Animal Behaviour 51:675-687. DOI: 10.1006/anbe.1996.0071

473

474 Childress MJ, Herrnkind WF. 2001a. The guide effect influence on the gregariousness of 475 juvenile Caribbean spiny lobsters. Animal Behaviour 62:465-472. DOI: 10.1006/anbe.2001.1760 476

477 Childress MJ, Herrnkind WF. 2001b. Influence of conspecifics on the ontogenetic habitat shift of 478 juvenile Caribbean spiny lobsters. Marine and Freshwater Research 52:1077-1084. DOI:

479 10.1071/MF01047

480 
481 Clark, J. 1968. Seasonal movements of striped bass contingents of Long Island Sound and the

482 New York Bight. Transactions of the American Fisheries Society 97(4):320-343. DOI:

483

10.1577/1548-8659(1968)97[320:SMOSBC]2.0.CO;2

484

485 Cobb JS. 1981. Behaviour of the Western Australian Spiny Lobster, Panulirus cygnus George, in 486 the Field and Laboratory. Australian Journal of Marine and Freshwater Research 32(3):399-

487 409. DOI: 10.1071/MF9810399

488

489 Cowan DF, Atema J. 1990. Moult staggering and serial monogamy in American lobsters, 490 Homarus americanus. Animal Behaviour 39(6):1199-1206. DOI: 10.1016/S0003-

$491 \quad 3472(05) 80792-4$

492

493 Darling J, Bagley M, Roman J, Tepolt C, Geller J. 2008. Genetic patterns across multiple

494 introductions of the globally invasive crab genus Carcinus. Molecular Ecology 17:4992-4992-

495 5007. DOI: 10.1111/j.1365-294X.2008.03978.x

496

497 Depledge MH. 1984. Cardiac activity in the intertidal crab Hemigrapsus sanguineus (De Haan). 498 Asian Marine Biology 1:115-123.

499

500 Everett R, Ruiz G. 1993. Coarse woody debris as a refuge from predation in aquatic

501 communities. An experimental test. Oecologia 93:475-475-486. DOI: 10.1007/BF00328954 502 
503 Freeman AS, Byers JE. 2006. Divergent Induced Responses to an Invasive Predator in Marine

504 Mussel Populations. Science 313:831-833. DOI: 10.1126/science.1125485

505

506 Freeman AS, Dernbach E, Marcos C, Koob E. 2014. Biogeographic contrast of Nucella lapillus

507 responses to Carcinus maenas. Journal of Experimental Marine Biology and Ecology 452:1-8.

508 DOI: 10.1016/j.jembe.2013.11.010

509

510 Gilbey V, Attrill MJ, Coleman RA. 2008. Juvenile Chinese mitten crabs (Eriocheir sinensis) in

511 the Thames estuary: distribution, movement, and possible interactions with the native crab

512 Carcinus maenas. Biological Invasions 10:67-77. DOI: 10.1007/s10530-007-9110-4

513

514 Gilman M, Grace SP. 2009. Use of Subtidal Habitat by the Asian Shore Crab Hemigrapsus

515 sanguineus in Long Island Sound. Northeastern Naturalist 16(3):481-487. DOI:

$516 \quad 10.1656 / 045.016 . n 314$

517

518 Gothland M, Dauvin JC, Denis L, Jobert S, Ovaert J, Pezy JP, Spilmont N. 2013. Additional

519 records and distribution (2011-2012) of Hemigrapsus sanguineus (De Haan, 1835) along the

520 French coast of the English Channel. Management of Biological Invasions 4(4):305-315. DOI:

$521 \quad 10.3391 / \mathrm{mbi} .2013 .4 .4 .05$

522

523 Gothland M, Dauvin JC, Denis L, Dufossé F, Jobert S, Ovaert J, Pezy JP, Rius AT, Spilmont N.

524 2014. Biological traits explain the distribution and colonisation ability of the invasive shore crab 
525 Hemigrapsus takanoi. Estuarine, Coastal and Shelf Science 142:41-49. DOI:

$526 \quad 10.1016 /$ j.ecss.2014.03.012

527

528 Griffen BD. 2006. Detecting emergent effects of multiple predator species. Oecologia

529

148(4):702-709. DOI: 10.1007/s00442-006-0414-3

530

531 Griffen BD, Byers JE. 2006. Partitioning mechanisms of predator interference in different

532 habitats. Oecologia 146:608-614. DOI: 10.1007/s00442-005-0211-4

533

534 Griffen BD, Guy T, Buck JC. 2008. Inhibition between invasives: a newly introduced predator

535 moderates the impacts of a previously established invasive predator. Journal of Animal Ecology

536 77:32-40. DOI: 10.1111/j.1365-2656.2007.01304.x

537

538 Griffen BD, Byers JE. 2009. Community impacts of two invasive crabs: the interactive roles of

539 density, prey recruitment, and indirect effects. Biological Invasions 11:927-940. DOI:

$540 \quad 10.1007 / \mathrm{s} 10530-008-9305-3$

541

542 Griffen BD, Riley ME. 2015. Potential impacts of invasive crabs on one life history strategy of

543 native rock crabs in the Gulf of Maine. Biological Invasions 17:2533-2544. DOI:

$544 \quad 10.1007 / \mathrm{s} 10530-015-0890-7$

545

546 Grove MW, Woodin SA. 1996. Conspecific Recognition and Host Choice in a Pea Crab, Pinnixa

547 chaetopterana (Brachyura: Pinnotheridae). Biological Bulletin 190:359-366. 
549 Hines A, Lipcius R, Haddon A. 1987. Population dynamics and habitat partitioning by size, sex, 550 and molt stage of blue crabs Callinectes sapidus in a subestuary of central Chesapeake Bay.

551 Marine Ecology Progress Series 36:55-64.

552

553 Hudson DM. 2011. Characteristics Contributing to Invasiveness of the Asian Shore Crab, 554 Hemigrapsus sanguineus. PhD dissertation, University of Connecticut, Storrs, CT.

556 Jensen GC, McDonald PS, Armstrong DA. 2002. East meets west: competitive interactions

557 between green crab Carcinus maenas, and native and introduced shore crab Hemigrapsus spp.

558 Marine Ecology Progress Series 225:251-262. DOI: 10.3354/meps225251

559

560 Jones PL, Shulman MJ. 2008. Subtidal-intertidal trophic links: American lobsters [Homarus

561 americanus (Milne-Edwards)] forage in the intertidal zone on nocturnal high tides. Journal of

562 Experimental Marine Biology and Ecology 361:98-103. DOI: 10.1016/j.jembe.2008.05.004

563

564 Jordan A, Herbert N, Steffensen J. 2005. Escape performance in three teleosts from West

565 Greenland. Polar Biology 28:164-167. DOI: 10.1007/s00300-004-0679-0

566

567 Jordan TS. 2010. The role of behavioral temperaments on the ecology of the Caribbean reef

568 octopus, Octopus briareus. Masters thesis, Clemson University, Clemson, SC. 
570 Karnofsky EB, Atema J, Elgin RH. 1989. Field observations of social behavior, shelter use, and

571 foraging in the lobster, Homarus americanus. The Biological Bulletin 176(3):239-246.

572

573 King S, Sheridan P. 2006. Nekton of New Seagrass Habitats Colonizing a Subsided Salt Marsh

574 in Galveston Bay, Texas. Estuaries and Coasts 29:286-296. DOI: 10.1007/BF02781997

575

576 Kraemer GP, Sellberg M, Gordon A, Main J. 2007. Eight-year record of Hemigrapsus

577 sanguineus (Asian Shore Crab) invasion in Western Long Island Sound estuary. Northeastern

578 Naturalist 14(2):207-224. DOI: 10.1656/1092-6194(2007)14[207:EROHSA]2.0.CO;2

579

580 Lazzari M, Sherman S, Kanwit J. 2003. Nursery use of shallow habitats by epibenthic fishes in

581 Maine nearshore waters. Estuarine, Coastal and Shelf Science 56:73-73-84 . DOI:

$582 \quad 10.1016 / \mathrm{S} 0272-7714(02) 00122-1$

583

584 Ledesma ME, O'Connor NJ. 2001. Habitat and diet of the non-native crab Hemigrapsus

585 sanguineus in southeastern New England. Northeastern Naturalist 8(1):63-78. DOI:

586 10.1656/1092-6194(2001)008[0063:HADOTN]2.0.CO;2

587

588 Lohrer AM, Whitlatch RB. 2002. Interactions among aliens: Apparent replacement of one exotic 589 species by another. Ecology 83(3):719-732. DOI: 10.1890/0012-

590 9658(2002)083[0719:IAAARO]2.0.CO;2

591 
592 Lohrer AM, Whitlatch RB, Wada K, Fukui Y. 2000. Home and away: comparisons of resource

593 utilization by a marine species in native and invaded habitats. Biological Invasions 2:41-57.

594 DOI: 10.1023/A:1010069327402

595

596 MacDonald JA, Roudez R, Glover T, Weis JS. 2007. The invasive green crab and Japanese shore

597 crab: behavioral interactions with a native crab species, the blue crab. Biological Invasions

598 9:837-848. DOI 10.1007/s10530-006-9085-6

599

600 McDermott JJ. 1998. The western Pacific brachyuran (Hemigrapsus sanguineus: Grapsidae), in

601 its new habitat along the Atlantic coast of the United States: geographic distribution and ecology.

602 ICES Journal of Marine Science 55:289-298. DOI: 10.1006/jmsc.1997.0273

603

604 Nevitt G, Pentcheff ND, Lohmann KJ, Zimmer RK. 2000. Den selection by the spiny lobster

605 Panulirus argus: testing attraction to conspecific odors in the field. Marine Ecology Progress

606 Series 203:225-231. DOI: 10.3354/meps203225

607

608 O'Neill DJ, Cobb JS. 1979. Some factors influencing the outcome of shelter competition in 609 lobsters (Homarus americanus). Marine Behaviour and Physiology 6(1):33-45. DOI:

$610 \quad 10.1080 / 10236247909378551$

611

612 Ortiz-León HJ, de Jesus-Navarrete A, Sosa Cordero E. 2007. Temporal and spatial distribution 613 of the crab Callinectes sapidus (Decapoda : Portunidae) in Chetumal Bay, Quintana Roo, 614 Mexico. Revista de Biología Tropical 55:235-245. 
615

616 Perkins-Visser E, Wolcott TG, Wolcott DL. 1996. Nursery role of seagrass beds: enhanced

617 growth of juvenile blue crabs (Callinectes sapidus Rathbun). Journal of Experimental Marine

618 Biology and Ecology 198:155-173. DOI: 10.1016/0022-0981(96)00014-7

619

620 Peterson BJ, Fournier AM, Furman BT, Carroll JM. 2014. Hemigrapsus sanguineus in Long

621 Island salt marshes: experimental evaluation of the interactions between an invasive crab and

622 resident ecosystem engineers. PeerJ 2:e472. DOI: $10.7717 /$ peerj.472

623

624 Pörtner HO. 2001. Climate change and temperature-dependent biogeography: oxygen limitation 625 of thermal tolerance in animals. Naturwissenshaften 88:137-146. DOI: 10.1007/s001140100216 626

627 Rasch, JA, O'Connor NJ. 2012. Development and behavior of megalopae of the non-native crab 628 Hemigrapsus sanguineus in response to chemical cues from coastal fishes. Journal of 629 Experimental Marine Biology and Ecology 416-417:196-201. DOI: 10.1016/j.jembe.2011.12.012 630

631 Richards RA, Cobb JS. 1986. Competition for shelter between lobsters (Homarus americanus) 632 and Jonah crabs (Cancer borealis): effects of relative size. Canadian Journal of Fisheries and 633 Aquatic Sciences 43(11):2250-2255. DOI: 10.1139/f86-276

634

635 Roman J, Darling JA. 2007. Paradox lost: genetic diversity and the success of aquatic invasions.

636 TRENDS in Ecology and Evolution 22(9):454-464. DOI: 10.1016/j.tree.2007.07.002

637 
638 Say T. 1817. An account of the Crustacea of the United States. Journal of the Academy of

639 Natural Sciences of Philadelphia 1:57-63.

640

641 Schofield P. 2003. Habitat selection of two gobies (Microgobius gulosus, Gobiosoma robustum):

642 influence of structural complexity, competitive interactions, and presence of a predator. Journal

643 of Experimental Marine Biology and Ecology 288:125-137. DOI: 10.1016/S0022-

644 0981(03)00004-2

645

646 Schultz ET, Lwiza KMM, Fencil MC, Martin JM. 2003. Mechanisms promoting upriver

647 transport of larvae of two fish species in the Hudson River estuary. Marine Ecology Progress

648 Series 251:263-277. DOI: 10.3354/meps 251263

649

650 Steinberg MK, Epifanio CE, Andon A. 2007. A highly specific chemical cue for the

651 metamorphosis of the Asian shore crab, Hemigrapsus sanguineus. Journal of Experimental

652 Marine Biology and Ecology 347:1-7. DOI: 10.1016/j.jembe.2007.02.005

653

654 Tolley S, Volety A, Savarese M, Walls L, Linardich C, Everham E. 2006. Impacts of salinity and

655 freshwater inflow on oyster-reef communities in Southwest Florida. Aquatic Living Resources

656 19:371-387. DOI: 10.1051/alr:2007007

657

658 van den Brink AM, Wijnhoven S, McLay CL. 2012. Competition and niche segregation

659 following the arrival of Hemigrapsus takanoi in the formerly Carcinus maenas dominated Dutch

660 delta. Journal of Sea Research 73:126-136. DOI: j.seares.2012.07.006 
661

662 van der Meeren GI. 2000. Predation on hatchery-reared lobsters released in the wild. Canadian 663 Journal of Fisheries and Aquatic Sciences 57:1794-1803. DOI: 10.1139/f00-134

664

665 Walton WC, MacKinnon C, Rodriguez LF, Proctor C, Ruiz GM. 2002. Effect of an invasive crab 666 upon a marine fishery: green crab, Carcinus maenas, predation upon a venerid clam, Katelysia 667 scalarina, in Tasmania (Australia). Journal of Experimental Marine Biology and Ecology 668 272:171-189. DOI: 10.1016/S0022-0981(02)00127-2

669

670 Wieters EA, Salles E, Januario SM, Navarrete SA. 2009. Refuge utilization and preferences 671 between competing intertidal crab species. Journal of Experimental Marine Biology and Ecology 672 374:37-44. DOI: 10.1016/j.jembe.2009.04.006

673

674 Williams AB, McDermott JJ. 1990. An eastern United States record for the western Indo-Pacific 675 crab, Hemigrapsus sanguineus (Crustacea: Decapoda: Grapsidae). Proceedings of the Biological 676 Society of Washington 103:108-109.

677

678 Zimmer-Faust RK, Spanier E. 1987. Gregariousness and sociality in spiny lobsters: implications 679 for den habitation. Journal of Experimental Marine Biology and Ecology 105:57-71. DOI:

$680 \quad 10.1016 / \mathrm{S} 0022-0981(87) 80029-1$

681

682

683 


\section{Figure Legends}

690

691 Fig. 1: Field and laboratory shelter setup. Over the course of several weeks, the diagrammed 692 artificial shelter was deployed at the northwest side of Pine Island, USA (41 $18^{\prime} 47.434^{\prime \prime}$ N, $69372^{\circ} 3^{\prime} 36.216^{\prime}$ W) by fixing it to the sediment for a 24 -hour soak of the treatments described in

694 the Methods. B) Shelter setup for direct shelter competition experiments between Hemigrapsus 695 sanguineus and Carcinus maenas, which was completed in an $18 \mathrm{~cm} \mathrm{x} 31 \mathrm{~cm}$ plastic box with 696 sand substrate for 24 hours. A $10 \mathrm{~cm}$ x $5.0 \mathrm{~cm}$ shelter, made from $6.35 \mathrm{~cm}$ PVC pipe with a 697 quarter of its circumference removed, was arranged in the container to have only one useable 698 opening.

699

700 Fig. 2: Seasonal subtidal shelter use. Seasonal subtidal shelter use across seasons for all

701 treatments for which there are seasonal data (control, Hemigrapsus sanguineus male, and $H$.

702 sanguineus female) in catch per unit effort (CPUE, in number of animals per number of tubes (n $703=180$ tubes for each bar)) mean \pm SE for: (A) Carcinus maenas, (B) Pagurus spp., (C)

704 Gobiosoma ginsburgi, and (D) Myoxocephalus aenaeus. Significance between seasons indicated 705 by brackets: “*” $=\mathrm{p}<0.05$, “**” $=\mathrm{p}<0.01$, “***” $=\mathrm{p}<0.001$. 
707 Fig. 3: Summer subtidal shelter use in hermit crabs and gobies. Summer subtidal shelter use

708 across treatments in catch per unit effort (CPUE, in number of animals per number of traps $(\mathrm{n}=$

70960 for each bar)) mean \pm SE for (top graph) hermit crab Pagurus spp. and (lower graph)

710 seaboard goby Gobiosoma ginsburgi. Treatments: $\mathrm{NC}=\mathrm{No}$ Crab, $\mathrm{HSM}=H$. sanguineus Male,

$711 \mathrm{HSF}=H$. sanguineus Female, $\mathrm{CMM}=C$. maenas Male, and $\mathrm{CMF}=C$. maenas Female. Bars

712 with the same letter are statistically similar $(\mathrm{p}>0.05)$.

713

714 Fig. 4: Summer shelter choice in Hemigrapsus sanguineus. Stated in catch per unit effort

715 (CPUE, in number of animals caught per number of tubes $(\mathrm{n}=60$ tubes for each bar)) mean \pm

716 SE. Treatments were: $\mathrm{HSm}=H$. sanguineus male, $\mathrm{HSf}=H$. sanguineus female, $\mathrm{CMm}=$

717 Carcinus maenas male, $\mathrm{CMf}=C$. maenas female. Results for shelter occupancy are shown for

718 A) intertidal male $H$. sanguineus, B) intertidal female $H$. sanguineus, and C) overall intertidal $H$.

719 sanguineus. Significance between treatments indicated by brackets: “*” $=p<0.05$, “**” $=p<$

$7200.01, “ * * * \cdots=\mathrm{p}<0.001$.

721

722

723 Fig. 5: Laboratory shelter competition between Hemigrapsus sanguineus and Carcinus maenas.

724 A) Fraction of each species in shelter after 24 hours of direct shelter competition between an

725 individual $H$. sanguineus and $C$. maenas. At the left side of the x-axis, H. sanguineus are larger

726 by carapace width (CW), and on the right, C. maenas are larger. $\mathrm{N}$ is between 4 and 17 for each

727 point. B) Fraction of each species dead after 24 hours of direct shelter competition between an

728 individual $H$. sanguineus and $C$. maenas. At the left side of the x-axis, $H$. sanguineus are larger,

729 and on the right, C. maenas are larger. $\mathrm{N}$ is between 4 and 17 for each point. 
731 Supplemental Fig. 1: Summer use of shelter in Carcinus maenas. Catch per unit effort (CPUE, in

732 number of animals caught per number of tubes $(\mathrm{n}=60$ tubes for each bar $))$ mean $\pm \mathrm{SE}$ A) $C$.

733 maenas use of subtidally- and intertidally-deployed shelters. B) Summer intertidal deployment of

734 multiple treatments (Treatments: $\mathrm{NC}=\mathrm{No}$ Crab, $\mathrm{HSM}=$ Hemigrapsus sanguineus $\mathrm{Male}$, $\mathrm{HSF}=$

735 H. sanguineus Female, $\mathrm{CMM}=C$. maenas Male, and $\mathrm{CMF}=C$. maenas Female). C) Summer

736 subtidal deployment in C. maenas. Significance between treatments or deployment depth

737 indicated by: “*” $=p<0.05, “ * * "=p<0.01$, “***” $=p<0.001$

738

739 Supplemental Fig. 2: Summer overall shelter use in Hemigrapsus sanguineus. Stated in catch

740 per unit effort (CPUE, in number of animals caught per number of tubes, $n=300$ tubes for each

741 bar) mean \pm SE. Significance between deployment depth indicated by: “*” $=p<0.05$, “**” $=p<$

$742 \quad 0.01, “ * * * "=p<0.001$ 


\section{Figure 1}

Field and laboratory shelter setup

Over the course of several weeks, the diagrammed an artificial shelter was deployed at the northwest side of Pine Island, USA ( $\left.41^{\circ} 18^{\prime} 47.434^{\prime \prime} \mathrm{N}, 72^{\circ} 3^{\prime} 36.216^{\prime \prime} \mathrm{W}\right)$ by fixing it to the sediment for a 24-hour soak of the treatments described in the Methods. B) Shelter setup for direct shelter competition experiments between Hemigrapsus sanguineus and Carcinus maenas, which was completed in an $18 \mathrm{~cm} \times 31 \mathrm{~cm}$ plastic box with sand substrate for 24 hours. A $10 \mathrm{~cm} \times 5.0 \mathrm{~cm}$ shelter, made from $6.35 \mathrm{~cm}$ PVC pipe with a quarter of its circumference removed, was arranged in the container to have only one useable opening.

\section{A}

\section{Scent animal}

\section{Benthic}

\section{Surface}

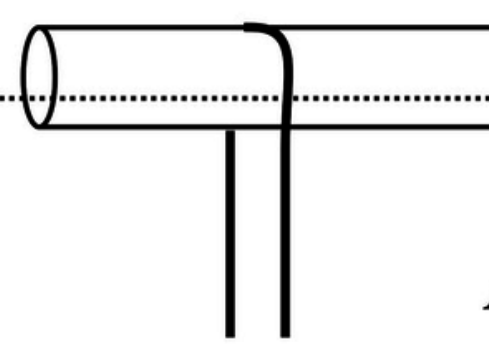

Artificial

shelter

Rebar

anchor

B

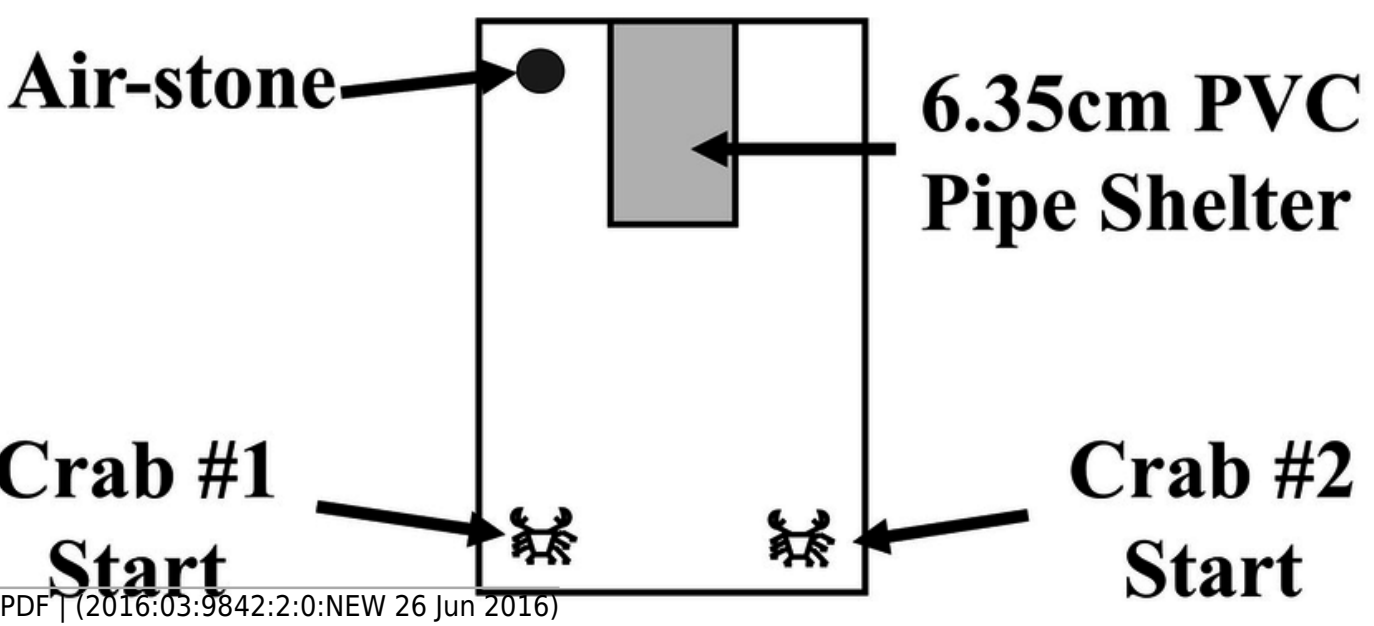




\section{Figure 2}

Seasonal subtidal shelter use

Seasonal subtidal shelter use across seasons for all treatments for which there are seasonal data (control, Hemigrapsus sanguineus male, and $H$. sanguineus female) in catch per unit effort (CPUE, in number of animals per number of tubes ( $n=180$ tubes for each bar)) mean \pm SE for: (A) Carcinus maenas, (B) Pagurus spp., (C) Gobiosoma ginsburgi, and (D) Myoxocephalus aenaeus. Significance between seasons indicated by brackets: “*” $=p<$ $0.05, “ * * "=p<0.01, “ * * * "=p<0.001$. 


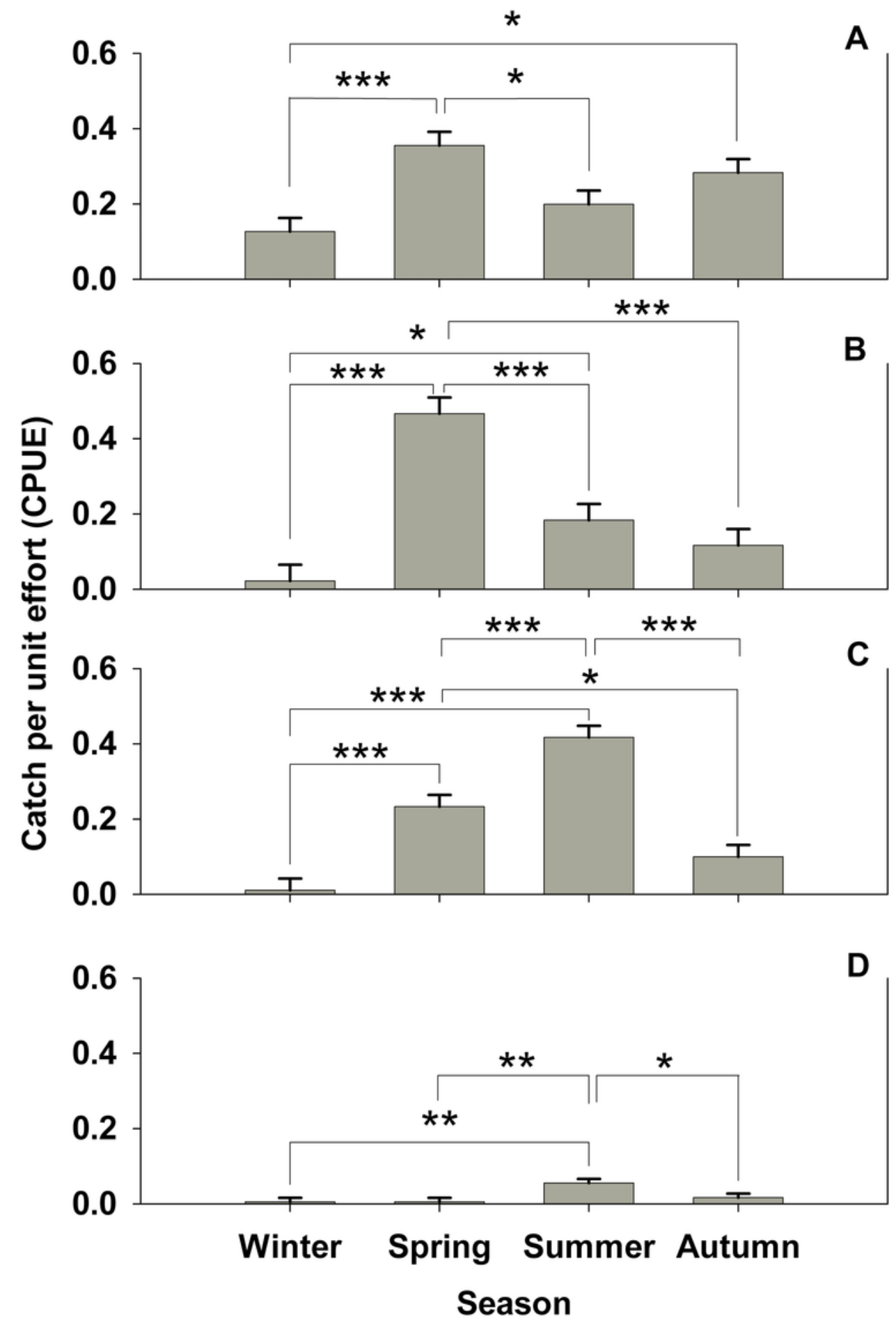




\section{Figure 3}

Summer subtidal shelter use in hermit crabs and gobies

Summer subtidal shelter use across treatments in catch per unit effort (CPUE, in number of animals per number of traps ( $n=60$ for each bar)) mean \pm SE for (top graph) hermit crab Pagurus spp. and (lower graph) seaboard goby Gobiosoma ginsburgi. Treatments: NC $=$ No $\mathrm{Crab}, \mathrm{HSM}=\mathrm{H}$. sanguineus Male, $\mathrm{HSF}=\mathrm{H}$. sanguineus Female, $\mathrm{CMM}=\mathrm{C}$. maenas Male, and $\mathrm{CMF}=C$. maenas Female. Bars with the same letter are statistically similar $(p>0.05)$. 


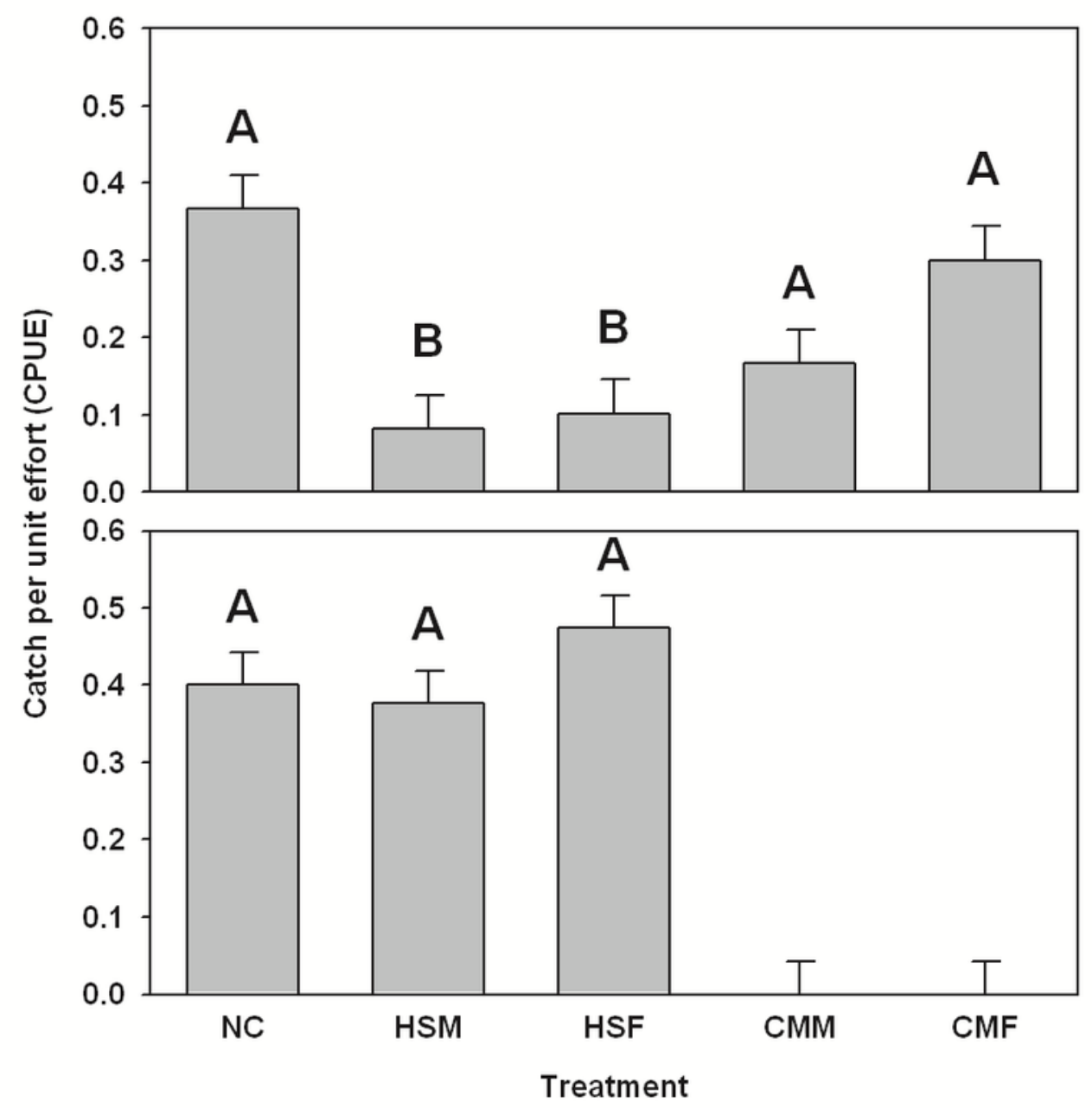


Figure 4

Summer shelter choice in Hemigrapsus sanguineus

Stated in catch per unit effort (CPUE, in number of animals caught per number of tubes $(n=$ 60 tubes for each bar)) mean $\pm \mathrm{SE}$. Treatments were: $\mathrm{HSm}=H$. sanguineus male, $\mathrm{HSf}=\mathrm{H}$. sanguineus female, $\mathrm{CMm}=$ Carcinus maenas male, $\mathrm{CMf}=\mathrm{C}$. maenas female. Results for shelter occupancy are shown for A) intertidal male $H$. sanguineus, B) intertidal female $H$. sanguineus, and C) overall intertidal $H$. sanguineus. Significance between treatments indicated by brackets: " $*$ " $=p<0.05$, “**" $=p<0.01$, “***" $=p<0.001$.

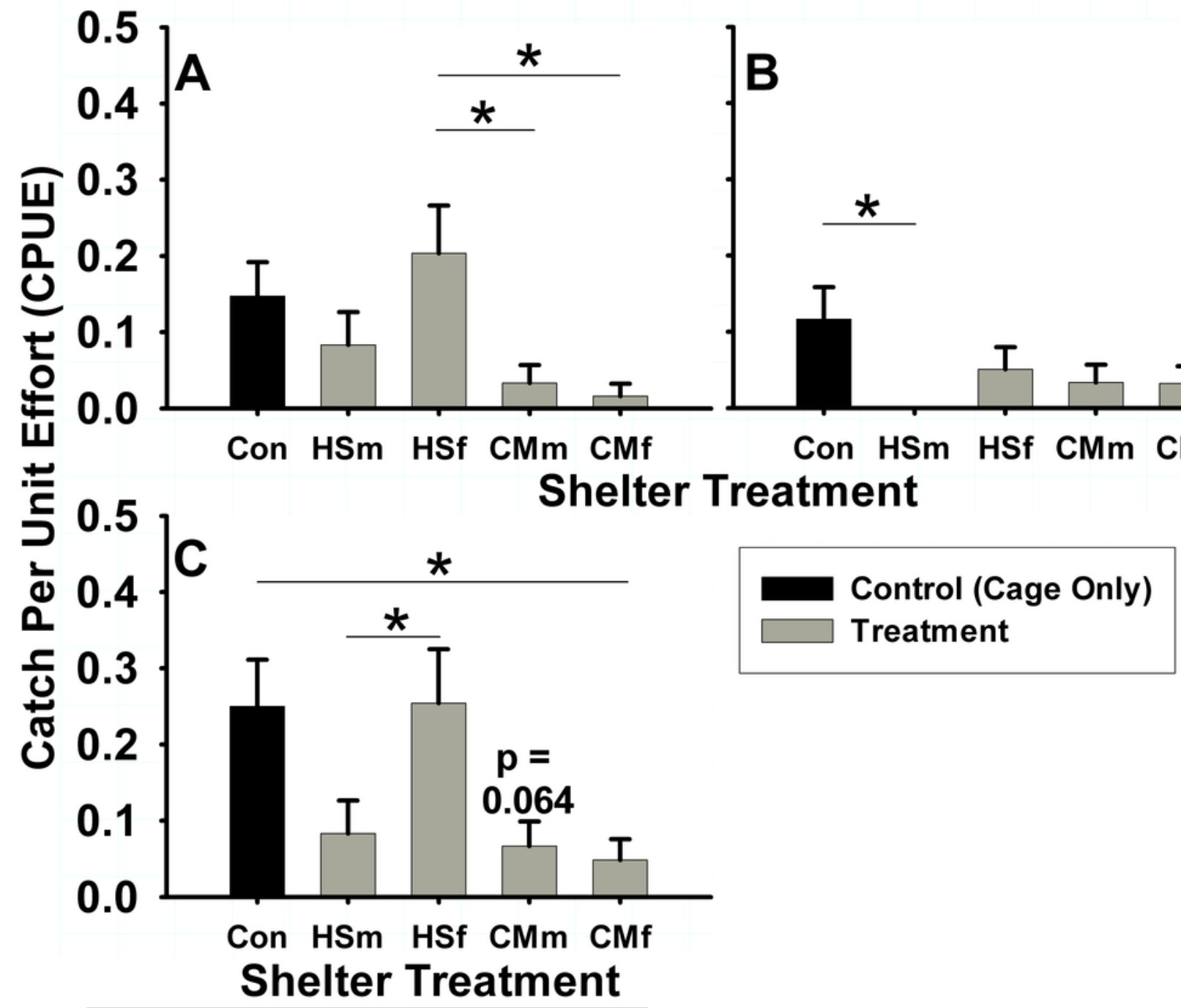


Figure $\mathbf{5}$ (on next page)

Laboratory shelter competition between Hemigrapsus sanguineus and Carcinus maenas.

A) Fraction of each species in shelter after 24 hours of direct shelter competition between an individual $H$. sanguineus and $C$. maenas. At the left side of the $x$-axis, $H$. sanguineus are larger by carapace width (CW), and on the right, $C$. maenas are larger. $N$ is between 4 and 17 for each point. B) Fraction of each species dead after 24 hours of direct shelter competition between an individual $H$. sanguineus and $C$. maenas. At the left side of the $x$-axis, $H$. sanguineus are larger, and on the right, $C$. maenas are larger. $\mathrm{N}$ is between 4 and 17 for each point. 
PeerJ
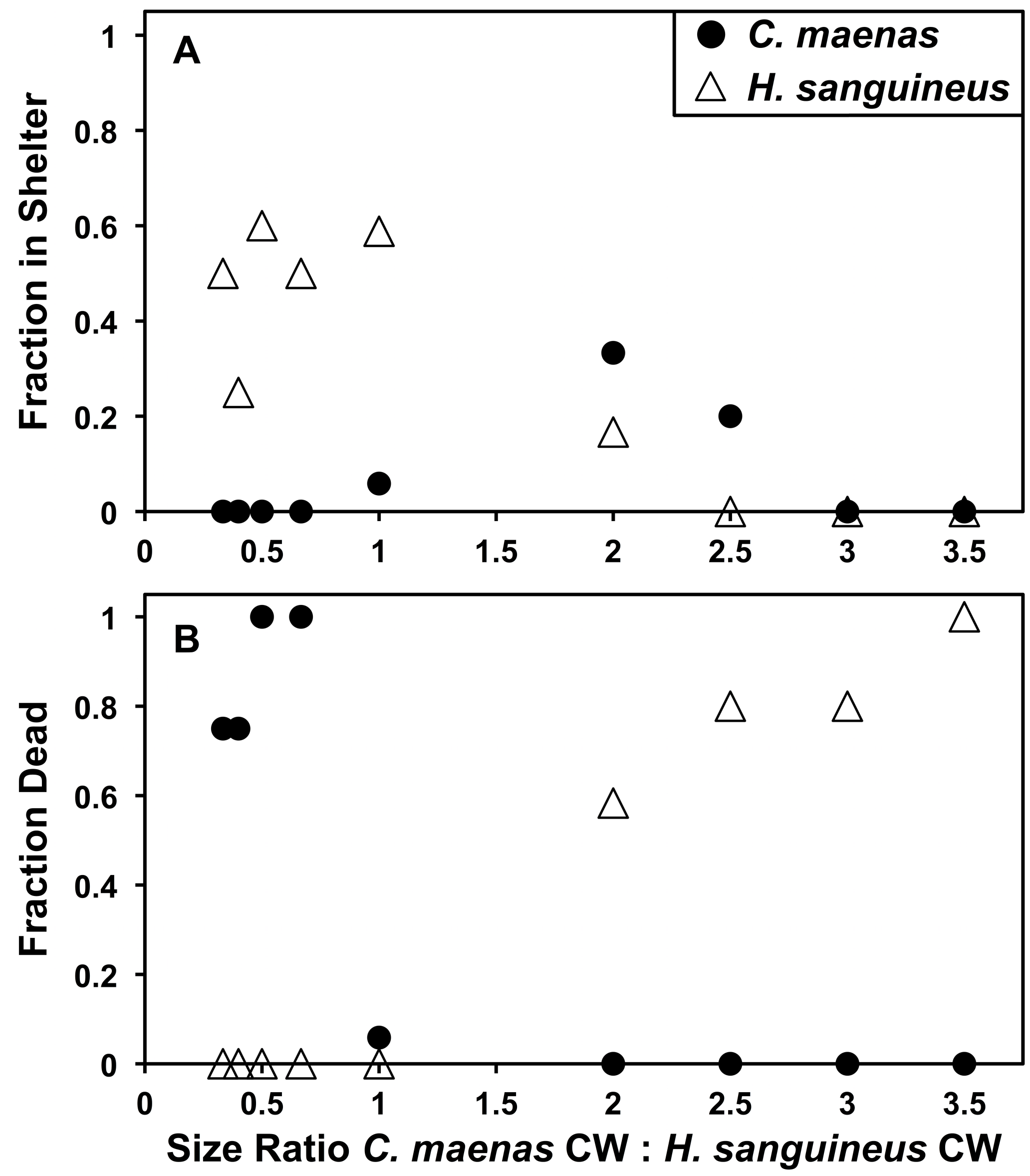